\title{
Effects of Dopamine Depletion on the Morphology of Medium Spiny Neurons in the Shell and Core of the Rat Nucleus Accumbens
}

\author{
G. E. Meredith, ${ }^{1}$ P. Ypma, ${ }^{1}$ and D. S. Zahm² \\ 'Department of Anatomy and Embryology, Faculty of Medicine, Vrije University, Amsterdam, The Netherlands and \\ ${ }^{2}$ Department of Anatomy and Neurobiology, St. Louis University School of Medicine, St. Louis, Missouri 63104
}

\begin{abstract}
Nucleus accumbens receives a dense dopaminergic innervation which is important in regulating motivated states of behavior such as goal-directed actions, stimulus-reward associations and reinforcement of addictive substances. The shell and core territories of this nucleus each receive functionally and morphologically distinct dopaminergic inputs and lesions of the ascending pathways totally deprive the core but not the shell of dopaminergic fibers. Medium spiny neurons are the principal targets of dopaminergic terminals. The present study explored whether the loss of dopamine inputs can affect these neurons and whether cells in the shell and core would be equally susceptible to such a loss. Intracellular injection in fixed slices and neuronal reconstruction were used to analyze the dendritic trees of 62 neurons in the shell and core of animals that received a unilateral, chronic 6-hydroxydopamine lesion of the medial forebrain bundle. In the dopamine-depleted core, dendrites are significantly shorter (16\% decrease) than in the intact core and in both the dopamine-depleted core and lateral shell, dendrites are less spiny than in respective control regions. Dopamine loss in the medial shell is associated with significantly more tortuous dendrites that are lower in spine density. However, the number of spines is not reduced which may mean that the increase recorded for segment length, although insignificant in tests, could be responsible for the change in spine density. These data suggest that the loss of dopamine can affect accumbal neuronal morphology and, moreover, can affect neuronal structures differentially in the shell and core.
\end{abstract}

[Key words: 6-OHDA, Lucifer yellow, ventral striatum, dopamine, spine, morphology, core, shell]

The ventral striatum, comprising the nucleus accumbens, ventral parts of the caudate-putamen, striatal parts of the olfactory tubercle and cell bridges interconnecting these structures (Heimer et al., 1985), is densely innervated by dopamine (DA)-contain-

Received Oct. 17, 1994; revised Dec. 19, 1994; accepted Dec. 21, 1994.

We are grateful to A. Pattiselanno, P. Goede and D. de Jong for technical support and to Dr. J. Golden and R. Agolia for assistance with the reconstruction program. We thank Dr. P. Digenbach and G. Doctor for advice and assistance with the statistical analysis and Drs. H. J. Groenewegen and B. L. Roberts for their comments on the manuscript. The work was supported by grants from the Hendrik Müller's Vaderlandsch Fonds, the Vrijvrowe van Renswoude Te Delft foundation and the Vrije Universiteit Fund to P.Y. and USPHS NS-23805 to D.S.Z.

Correspondence should be addressed to Dr. G. E. Meredith, Department of Anatomy, Royal College of Surgeons in Ireland, 123 St. Stephen's Green, Dublin 2, Ireland.

Copyright (C) 1995 Society for Neuroscience $0270-6474 / 95 / 153808-13 \$ 05.00 / 0$ ing fibers (Andèn et al., 1966; Beckstead et al., 1979; Voorn et al., 1986). The nucleus accumbens has a morphologically and neurochemically distinct shell which receives DA fibers primarily from mesolimbic neurons in the ventral tegmental area and retrorubral field (Deutch et al., 1988), and a core which is innervated by mesostriatal fibers from the substantia nigra pars compacta as well as by mesolimbic fibers (Nauta and Domesick, 1984; Groenewegen et al., 1991). Dopaminergic axon terminals form predominantly axodendritic terminals in the shell but approximately equivalent numbers of axodendritic and axospinous synapses in the core (Zahm, 1992). In a manner consistent with the morphological data, DA differentially modulates the synaptic responses of shell and core neurons (Pennartz et al., 1992b) and DA receptor antagonism is accompanied by distinct changes in the expression of c-fos and Fos-related antigens in the shell and core (Deutch et al., 1992; Dilts et al., 1993). Finally, DA receptor agonists and antagonists alter neuronal dye coupling, differentially in the shell and core (O'Donnell and Grace, 1993).

Neurons in the core project to the dorsolateral part of the ventral pallidum, the subthalamic nucleus and the substantia nigra pars compacta (Groenewegen and Berendse, 1990; Zahm and Heimer, 1990; Heimer et al., 1991; Zahm and Heimer, 1993; Groenewegen et al., 1994; but see Denlau et al., 1994). Cells in the shell project to the neurochemically distinct ventromedial part of the ventral pallidum (Zahm and Heimer, 1990), extended amygdala (Alheid and Heimer, 1988), lateral hypothalamus, and mesencephalic tegmentum (Groenewegen and Russchen, 1984; Heimer et al., 1991; Zahm and IIeimer, 1993). Considering the distinct nature of these efferent pathways, activation of shell and core output neurons would be expected to produce different effects, both physiologically and behaviorally. Accordingly, a behavioral dissociation between these regions has recently been shown (Maldonado-Irizarry and Kelley, 1993).

The projection neurons of nucleus accumbens are medium in size and have spiny dendrites. Medium spiny neurons in the shell and particularly in its medial part, have fewer primary dendrites with fewer dendritic segments and lower spine densities than those in the core (Meredith et al., 1992). Insofar as basal and stimulated DA utilization differs between the core and shell (Deutch and Cameron, 1991), DA may contribute to the maintenance of these morphological differences. Dopamine depletion alters neuronal structure in the dorsal striatum (Ingham et al., $1989,1991)$ and, presumably, in the ventral striatum as well, although this remains to be demonstrated experimentally. The present report describes experiments to test whether ventral striatal ncuronal morphology is altcred by DA depletion and whether any changes are expressed differently in the core and shell. 


\section{Materials and Methods}

Thirty-two adult, male Wistar rats (Harlan-Centraal Proefdierbedrijf, Zeist, The Netherlands), weighing 250-325 gm were used in the present study. Sixty minutes after having received an intraperitoneal injection of desmethylimipramine ( $25 \mathrm{mg} / \mathrm{kg}$ in physiological saline, RBI, USA), the animals were deeply anesthetized with a 4:3 mixture of Aescoket $(1 \%$ ketaminum- $\mathrm{HCl})$ and Rompun (2\% xylazine- $\mathrm{HCl}$; both $1 \mathrm{ml} / \mathrm{kg}$, i.m). Each animal was placed in a stereotaxic frame, the skull was opened and $2.5 \mu \mathrm{l}$ of a 6-hydroxydopamine (6-OHDA) solution (4 $\mu \mathrm{g}$ / $\mu l$ of the bromide in distilled water with $0.04 \%$ ascorbic acid) was injected unilaterally in the medial forebrain bundle (MFB) over a 15 min period. The needle of the Hamilton syringe was left in place for an additional $15 \mathrm{~min}$ before being removed. Having recovered from anesthesia, the animals were returned to their cages where they were given ral clow and water ad lib. From 9 to $13 \mathrm{~d}$ after the lesions were made, rats were injected intraperitoneally with apomorphine $(0.25 \mathrm{mg} /$ $\mathrm{kg}$, Sigma) in distilled water. After $30 \mathrm{~min}$, the number and direction of rotations in a large circular bowl were recorded. Animals turning away from the lesion more than 200 times during a 45 min test period are reported to have a striatal DA depletion of more than $90 \%$ (Hefti et al., 1980). Rats that met this criterion were kept for further work.

Twenty-one days after the lesions were made, the rats were reanesthetized with an overdose of sodium pentobarbital $(60 \mathrm{mg} / \mathrm{kg}$ i.p.) and perfused transcardially with Ringer's solution, followed immediately by $500 \mathrm{ml}$ of a solution containing $4 \%$ paraformaldehyde, $15 \%$ saturated picric acid and $0.05 \%$ glutaraldehyde in $0.1 \mathrm{M}$ phosphate buffer $(\mathrm{pH}$ 7.4) at room temperature during a period of $15 \mathrm{~min}$ or less. Following removal of each brain, the forebrain and midbrain were blocked and transverse, $300 \mu$ in thick slices of the rostral forebrain were cut alternately with $50 \mu \mathrm{m}$ sections with a Vibratome. In addition, $60 \mu \mathrm{m}$ sections were cut transversely through the midbrain. Both forebrain and midbrain sections were subjected to an immunohistochemical protocol with antibodies directed against tyrosine hydroxylase, as described below

Intracellular injection. The injection procedure is described elsewhere (Meredith and Arbuthnott, 1993). Briefly, the slices were placed for $1-3 \mathrm{~min}$ in a $10^{-7} \mathrm{M}$ solution of 4,6 diamidino-2-phenylindole (DAPI; Sigma) in $0.1 \mathrm{M}$ phosphate buffer which served as a counterstain for neuronal nuclei. Numerous neurons containing the fluorescent marker DAPI, were impaled in intact and DA-depleted nucleus accumbens and injected with a $4 \%$ solution of Lucifer yellow (LY) made up in distilled water (electrode resistance, 80-250 M $\Omega$ ). Slices were then placed in a solution of $20 \%$ dintethyl sulfoxide in $0.1 \mathrm{M}$ phosphate buffer, $\mathrm{pH} 7.4$, at $4^{\circ} \mathrm{C}$ and cut transversely at $40 \mu \mathrm{m}$ on a freezing microtome the following day.

Immunohistochemistry. The sections cut from the slices were immunoreacted with antibodies directed against LY. The incubation medium consisted of gelatin $(0.25 \%)$ and TBS-Tx $(0.5 \%$ Triton X-100 in $0.05 \mathrm{M}$ Tris-buffered saline; $0.9 \% \mathrm{NaCl}$ ); sections were rinsed between incubations in $0.05 \mathrm{M}$ Tris- $\mathrm{HCl}$ buffer, $\mathrm{pH}$ 7.6. Sections were incubated in rabbit anti-I,Y (kindly given by Dr. Bastiani, University of Utah, Salt Lake City, UT; Taghert et al., 1982) diluted 1:10,000 to 12,000 , overnight at $4^{\circ} \mathrm{C}$, followed by swine anti-rabbit $\mathrm{IgG}, 1: 150$, for $45 \mathrm{~min}$ at room temperature and, thereafter, rabbit peroxidase-antiperoxidase complex (PAP), diluted $1: 150$, for $45 \mathrm{~min}$ at room temperature. The sections were then reacted for approximately $20 \mathrm{~min}$ in $0.05 \% 3,3^{\prime}$ diaminobenzidine (DAB) with $1 \%$ ammonium nickel sulphate in 0.05 $M$ Tris-HCL buffer and $0.01 \% \mathrm{H}_{2} \mathrm{O}_{2}$. In order to stain the spines of neurons maximally, sections were reincubated in swine anti-rabbit IgG followed by rabbit PAP and reacted for $10-15 \mathrm{~min}$ in the DAB solution without ammonium nickel sulfate for $15 \mathrm{~min}$ or until the dendrites and spines of the injected cells appeared blue-black. The sections were mounted onto glass slides in serial order from $0.2 \%$ buffered gelatin solution, dehydrated, and coverslipped.

Sections from the forebrain and midbrain were incubated for $30 \mathrm{~min}$ in $10 \%$ normal goat serum in TBS at room temperature and then in mouse anti-tyrosine hydroxylase (Incstar, USA), 1:2000, at $4^{\circ} \mathrm{C}$ for $24-$ $48 \mathrm{hr}$ followed by an overnight incubation in goat anti mouse IgG, 1:50, and thereafter, another $24 \mathrm{hr}$ incubation in monoclonal rat PAP, 1:100 (Sternberger-Meyer, USA). A DAB reaction followed for 10-15 min.

Analysis. Intracellularly injected, LY-innmunoreacled neurons were selected for analysis if they fulfilled the following criteria: (1) they were medium spiny neurons and their dendritic processes were filled completely with LY, (2) they could be assigned unambiguously to the shell or core, and (3) during injection, LY did not spread into neighboring neurons or processes. The territorial assignment of neurons was accomplished by relating the location of injected cells to shell and core borders which were apparent in tyrosine hydroxylase-immunoreacted sections from the intact hemisphere. Since sections from the intact side could not be matched precisely to those from the lesioned hemisphere, care was taken to select neurons well within territorial borders. Cells from the rostral pole were not analyzed.

Approximately 400 cells were injected in both the DA-depleted and intact sides of the nucleus. Seventy-three neurons were reconstructed, and 62 of those were analyzed morphometrically. Using a light microscope equipped with a $100 \times$ oil-immersion objective and coupled to hardware and a software package dedicated to neuron reconstruction (Neuron Tracing System, Eutectic Electronics Inc., Raleigh, NC), each neuron was digitized in $x_{-}^{-}, y_{-}$, and $z$-coordinates. Primary dendrites were merged with the cell soma and each dendritic tree was reassembled by matching the truncated ends of dendrites in adjacent sections and merging them. Spines were recorded as points and accurately represented in the reconstruction drawings. Segment length was measured on line by the computer and spine density and dendritic tortuosity were calculated as functions of segment length.

Comparisons of neurons within and hetween territories were made but because cells near the surfaces of the slices were invariably injected, dendrites that would have extended above the slice surface were truncated during slice preparation. Consequently, this permitted the analysis of some but never all dendrites of any given neuron. Thus, morphometric parameters were evaluated using pooled dendritic segments, a segment being defined as the length between the perikaryon and the first bifurcation, between two branch points or between the most distal bifurcation and the end of the dendrite.

The length (in micrometers), tortuosity (segment length/radial distance between proximal and distal ends of a segment) and the density (spines $/ \mu \mathrm{m}$ ) and number of spines were recorded for each segment. Since dense immunoreaction product frequently accumulated around cell bodies (see, e.g., Figs. $3 C, 4 A$ ), perikaryal measurements were considered unreliable and were not included in the analysis. Consecutive branch orders $1^{\circ}, 2^{\circ}, 3^{\circ}$, etc. were designated, respectively, as the dendritic segments between the soma and the first, the first and the second, the second and the third, etc. bifurcations for each dendritic arbor of a neuron.

Differences between accumbal regions on the control side and between intact and DA-depleted hemispheres were analyzed statistically. Pooled values were examined with a Kolmogorov-Smirnov test to determine if they were distributed normally and normally distributed data were tested with the Student's $t$ test for independent measures. Other data were assessed with the Mann-Whitney $U$ test. Neuronal differences within each accumbal territory were assessed with a Kruskal-Wallis one-way analysis of variance. Medians and ranges and, where valid, means \pm standard deviations were computed for pooled segments from each territory.

\section{Results}

\section{Evaluation of lesions}

Necrosis near the midline in the caudal diencephalon was evident in transverse sections through the lesion site and tyrosine hydroxylase-positive fibers appeared to be absent from the ipsilateral MFB. The accumbal core was almost totally depleted of tyrosine hydroxylase immunoreactivity ipsilateral to the lesion (compare sides of Fig. 1A) as was the shell, except for its medial part where some immunoreactive fibers typically remained (Fig. 1B).

\section{General morphology of intracellularly injected neurons}

Generally, spiny neurons were injected although a small number of aspiny cells and an occasional glial cell were also filled. Only spiny neurons from middle to caudal levels of nucleus accumbens were selected for analysis (Fig. 2). Filled neurons in the rostral pole were rejected inasmuch as core and shell are not discernible rostrally (Deutch and Cameron, 1991; Zahm and Brog, 1992).

Photomicrographs and digitized reconstructions of filled neurons from DA-depleted and intact sides of the core and shell are 

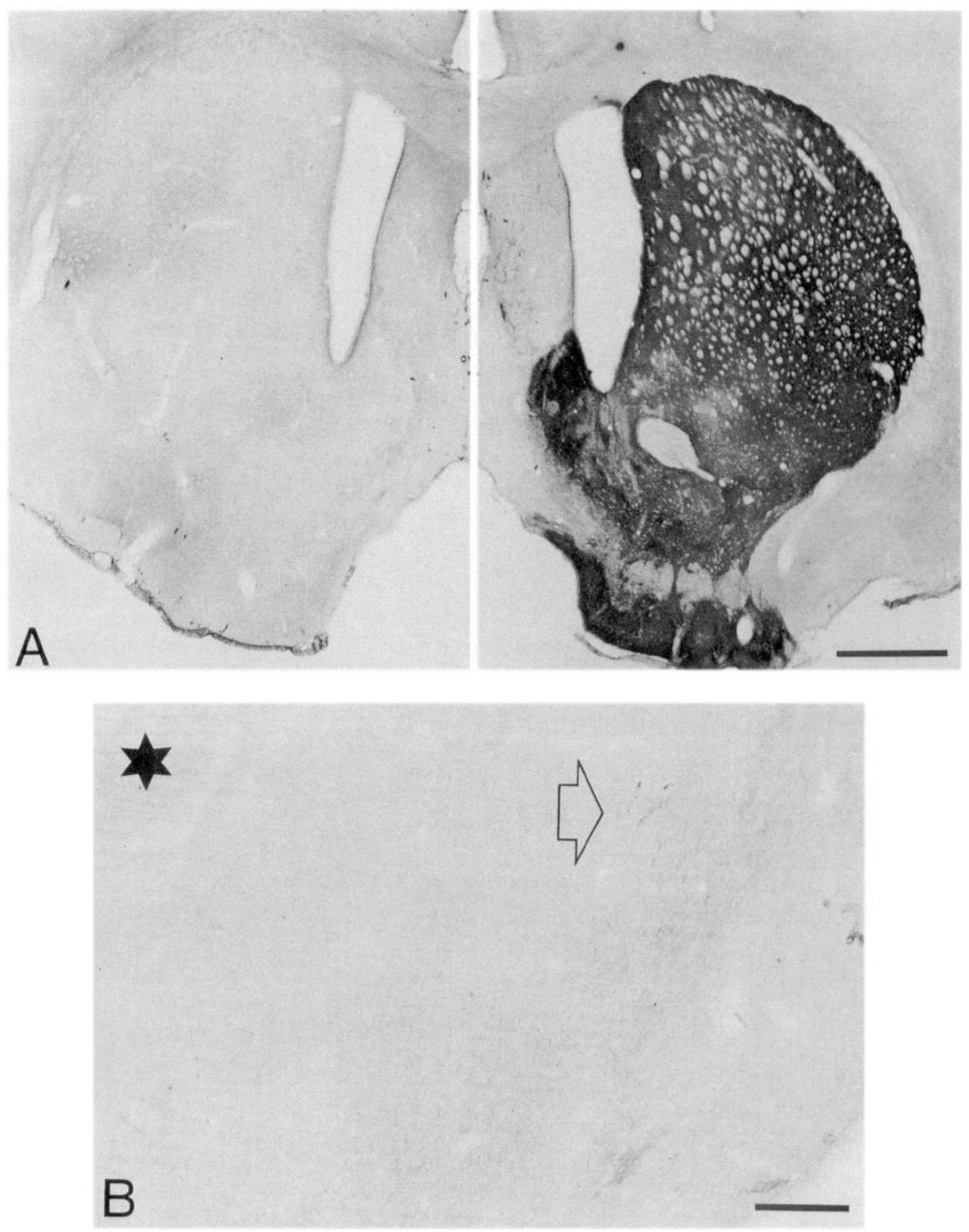

Figure 1. A, Photomicrograph of tyrosine hydroxylase immunoreactivity in a transverse section through the brain of a rat that received a unilateral injection of 6-OHDA in the medial forebrain bundle 21 days earlier. Note the near complete absence of tyrosine hydroxylase immunoreactivity on one side. $B$, Higher magnification of a portion of the medial accumbal shell in the DA-depleted hemisphere. Note that remaining tyrosine hydroxylase-immunoreactive fibers and varicosities are visible (open arrowhead). The star $(B)$ marks the location of the anterior commissure. Scale bars: $A, 500 \mu \mathrm{m} ; B, 100 \mu \mathrm{m}$.

illustrated in Figures 3 and 4, respectively. The cell bodies of neurons in the DA-depleted and control sides of the brain appear round to oval in shape (Figs. 3, 4). Each primary dendrite gives rise to a tree consisting of as many as nine branch orders in the core and eight in the shell. Dendrites are aspiny initially and spines appear after 5-20 $\mu \mathrm{m}$, typically at the first branch point
(Fig. 3A-D). Individual spines vary in length and shape (Fig. 5). Axons were never filled beyond approximately $100 \mu \mathrm{m}$.

The dendrites of neurons in the DA-depleted hemisphere appear to be more tortuous, especially at their distal tips, than their counterparts in the intact side (Fig. 6). Moreover, the density of spines seems to vary between neurons, between dendrites of the 


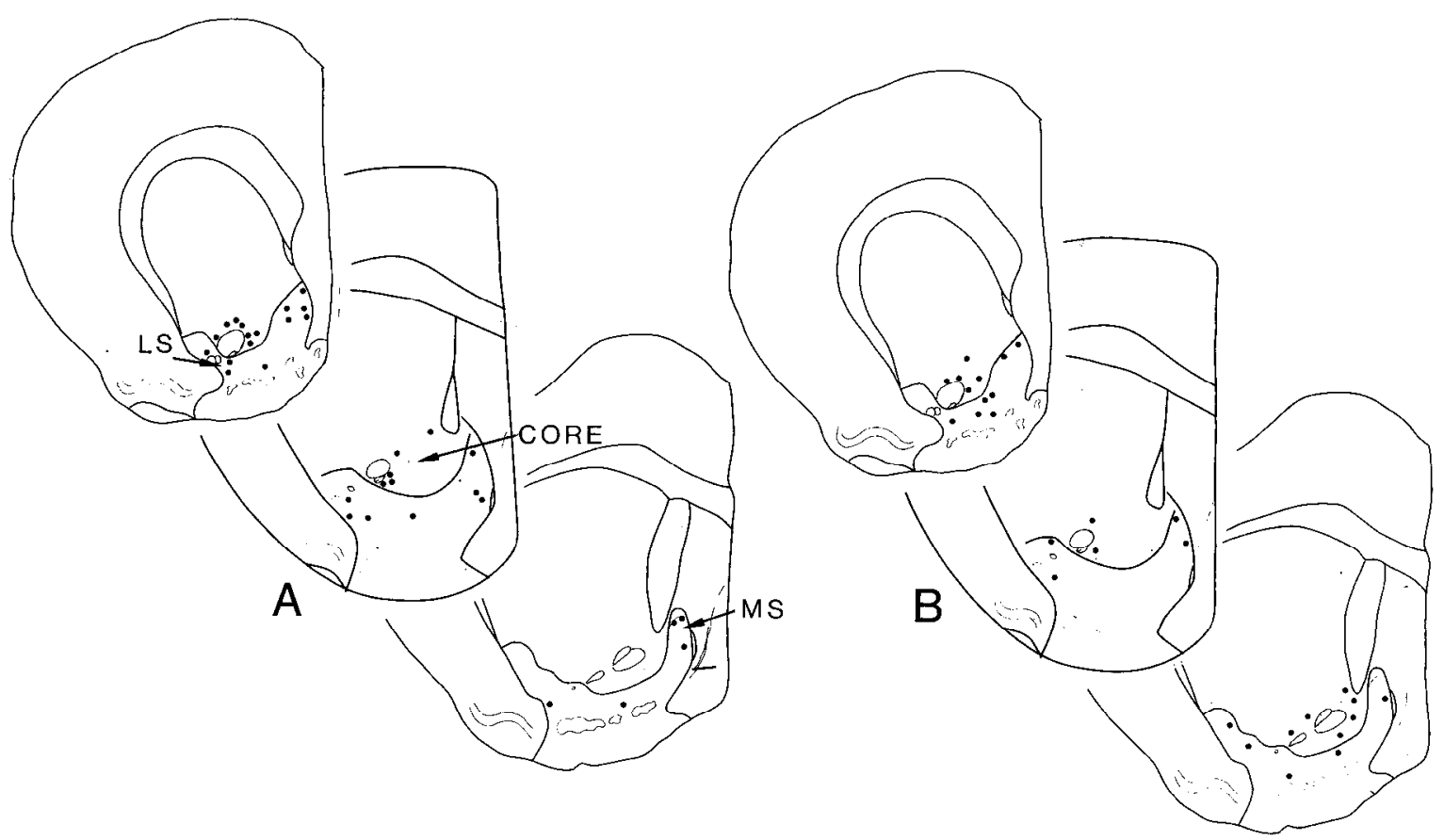

Figure 2. Diagrams showing the position of neurons filled with LY (solid circles) in sections through mid- to caudal levels of the nucleus accumbens. Core, lateral shell $(L S)$ and medial shell $(M S)$ are marked and $A$ shows cells injected in the control side; $B$ shows neurons filled in the DA-depleted hemisphere.

same neuron, and even between different parts of the same dendritic segment (Fig. 5C). These features are particularly pronounced in the DA-depleted hemisphere. Occasionally, dendrites in the DA-depleted side appeared to end in a cone-like process (Fig. 5D).

\section{Quantitative analysis of reconstructed neurons}

Intraterritorial comparisons. There is considerable variability among neurons in any one territory. In the intact hemisphere, cells in the medial and lateral shell and in the core differ significantly (Kruskal-Wallis ANOVA) for measures of tortuosity ( $p=0.008, p<0.0001, p<0.0001$, respectively) and spine density ( $p=0.001, p=0.02, p<0.0001$, respectively).

In the DA-depleted hemisphere, core neurons differ in the length $(p=0.001)$ and tortuosity $(p<0.0001)$ of their segments and in the density $(p<0.0001)$ and number of spines $(p=$ $0.001)$. Medial and lateral shell cells differ in spinc density ( $p$ $<0.0001$ and $p=0.003$, respectively) and tortuosity of their segments $(p<0.0001, p=0.002$, respectively). Such great variability between neurons within each region indicates that comparisons between intact and DA-depleted territories would be difficult to interpret using data for whole cells. Consequently, lesion effects were tested with values derived from pooled dendritic segments from each territory.

Interterritorial comparisons within the intact hemisphere. Comparisons of pooled segments in the intact hemisphere revealed differences between the core, medial shell and lateral shell in all parameters except dendritic segment length (Table 1). Dendritic segments in the entire shell are significantly less tortuous $(p<0.01$, Mann-Whitney $U$ ) with fewer spines (density, $p<0.05$; number, $p<0.05$ ) than those in the core. When the shell is divided into medial and lateral subterritories and these are assessed scparately, the medial shell segments are significantly less tortuous $(p<0.01)$ and have lower numbers $(p$
$<0.05)$ and densities $(p<0.01)$ of spines than those in the core; they also have significantly lower numbers $(p<0.05)$ and densities $(p<0.01)$ of spines than segments in the lateral shell. In addition, segments in the lateral shell are significantly less tortuous $(p<0.01)$ than those in the core but do not differ from the latter in number and density of spines.

Comparisons between intact and DA-depleted hemispheres. The loss of DA in the core is accompanied by decreases in the density and numbers of spines but not by changes in the length and tortuosity of segments (Table 1). However, terminal dendritic segments in the core are significantly shorter with DA depletion ( $p=0.009$, Mann-Whitney $U$ ) and the segments belonging to the first three branch orders are significantly more tortuous (Fig. 6A) on the DA-depleted side as compared to the intact side $(p=0.02$, Mann-Whitney $U$ ).

If the shell is considered in its entirety, the loss of DA is accompanicd by a significant reduction in spinc density and a significant increase in tortuosity for all segments and for all branch orders, but not by a change in the length of dendritic segments or in the numbers of spines (Table 1). However, when the shell is divided into medial and lateral parts and each is tested separately, a significant reduction in the density and numbers of spines is associated with DA-depletion in the lateral shell (compare Fig. $5 C, D$ ), but there is no change in the length and tortuosity of segments (Table 1). In the medial shell, only the tortuosity of segments (Fig. $6 B$ ) is significantly different, that is, higher with the lesion (Table 1) but it is noteworthy that even though the difference between segment length in the intact and DA-depleted medial shell is not significant ( $p=0.1$, MannWhitney $U$ ), the median value for length is considerably greater on the DA-depleted side (Table 1).

The ranges of values for dendritic features in the DA-depleted hemisphere are always greater than those for the same features on the intact side (Table 1) which suggests that some segments 

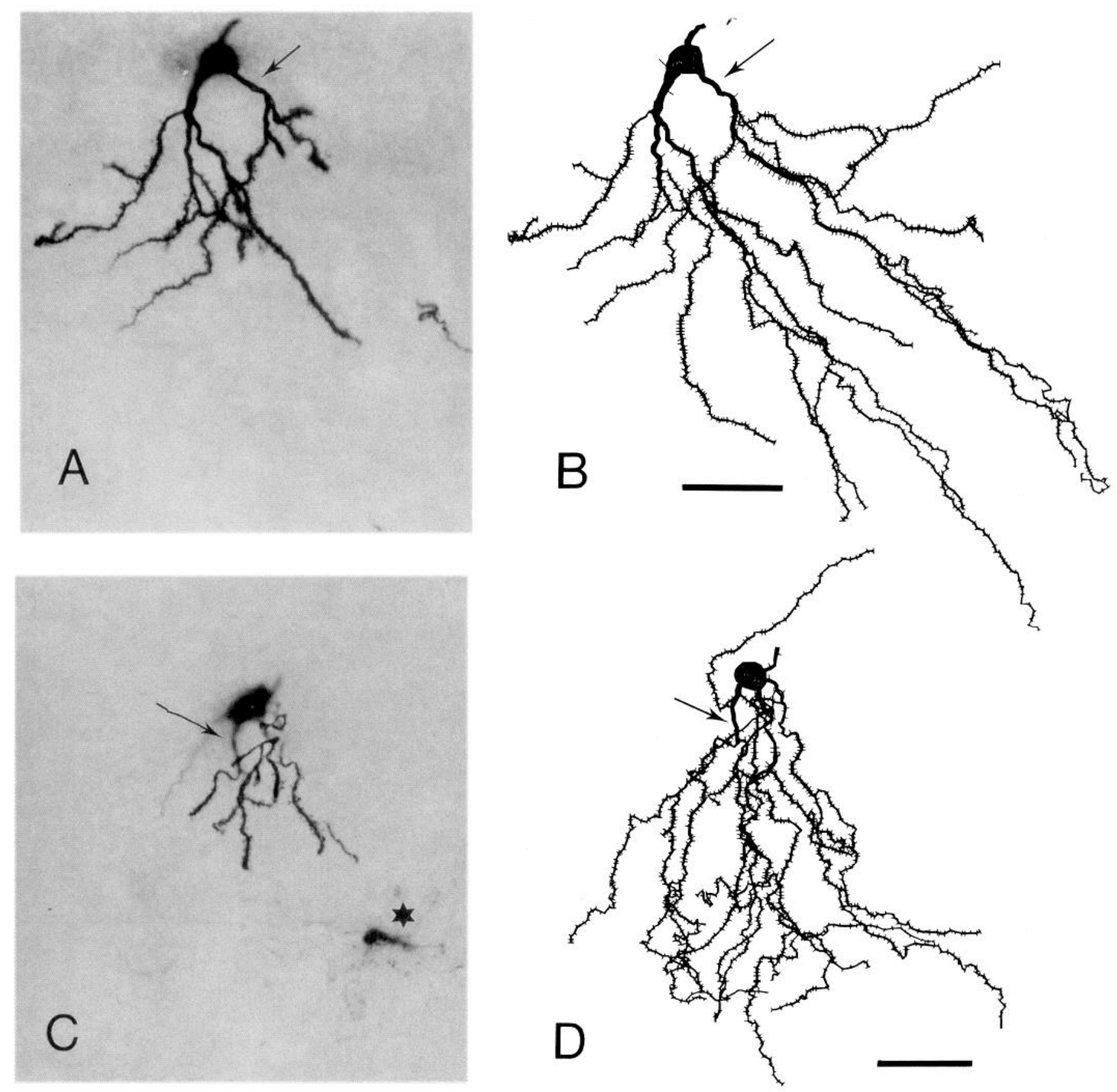

Figure 3. Photomicrographs of two LY-immunoreacted core neurons $(A, C)$ found in the first section of a slice and the full reconstructions of those neurons $(B, D) . A$ and $B$ are from the intact hemisphere and $C$ and $D$ from the DA-depleted core. Arrows point to the proximal aspiny segments of these cells. Note that spines begin at or beyond the first branch point. A star marks a filled cell with filamentous dendrites. Scale bars, $25 \mu \mathrm{m}$.

may be more affected than others. When spine density is plotted against segment length for all regions (Fig. $7 A-F$ ), there is great scatter in density values for segments less than $50 \mu \mathrm{m}$ in length. Furthermore, spine densities are normally distributed for segments longer than $50 \mu \mathrm{m}$ (not significant, Kolmogorov-Smirnov test). Statistical analysis revealed that core segments longer than $50 \mu \mathrm{m}$ do not differ in length and tortuosity with DA depletion but are significantly reduced in mean spine density $(t=4.3$, df $=396, p<0.0001)$ and in the numbers of spines $(p<0.0001$, Mann-Whitney $U$ ). Mean spine density for segments longer than

Figure 4. Photomicrographs of LY-immunoreacted medial shell neurons $(A, C)$ found in the first section of a slice and the full reconstructions of those neurons $(B, D) . A$ and $B$ are from the intact hemisphere and $C$ and $D$ from the DA-depleted side. Arrows in $D$ point out the tortuous course of some segments in the DA-depleted hemisphere. Scale bars, $25 \mu \mathrm{m}$. 

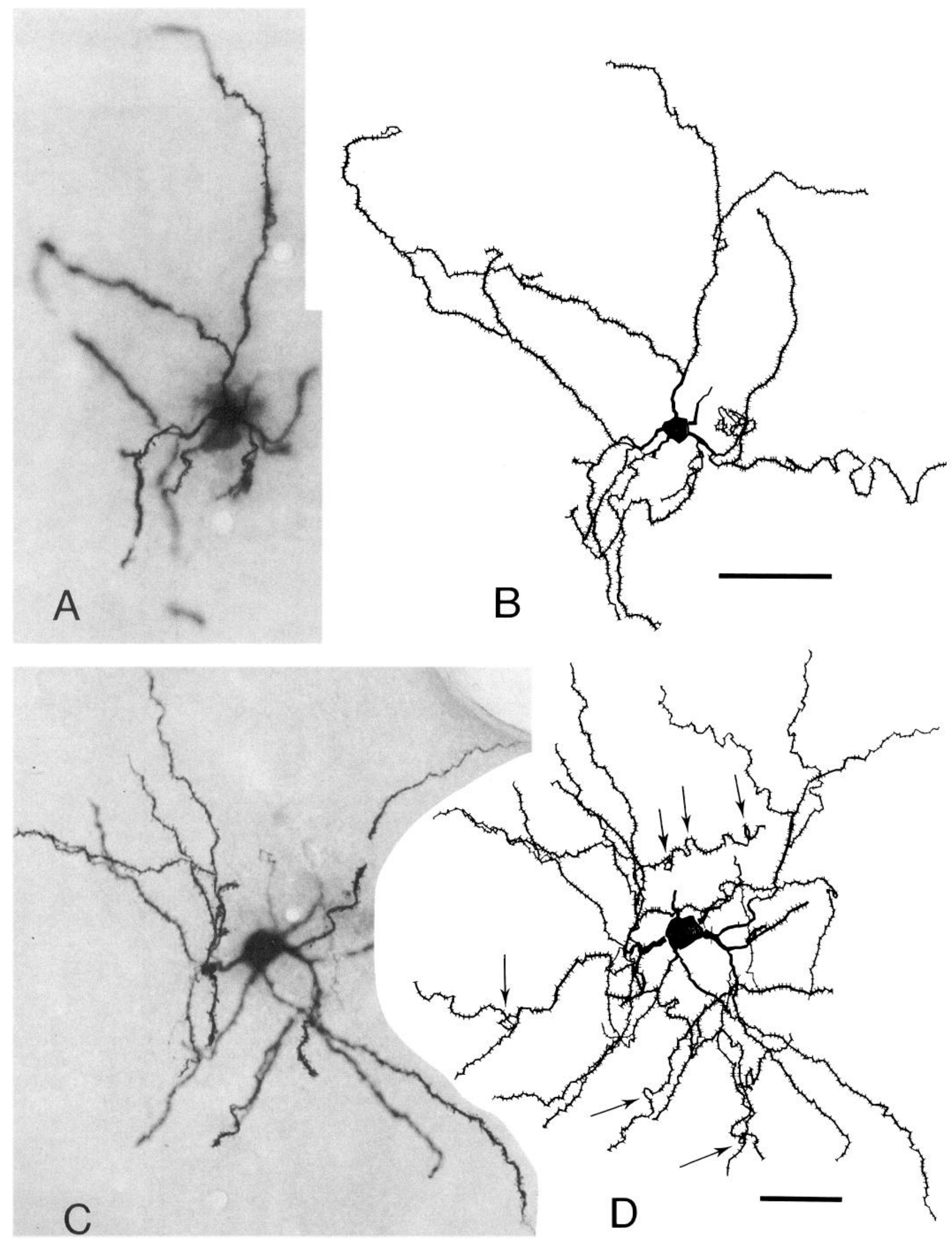

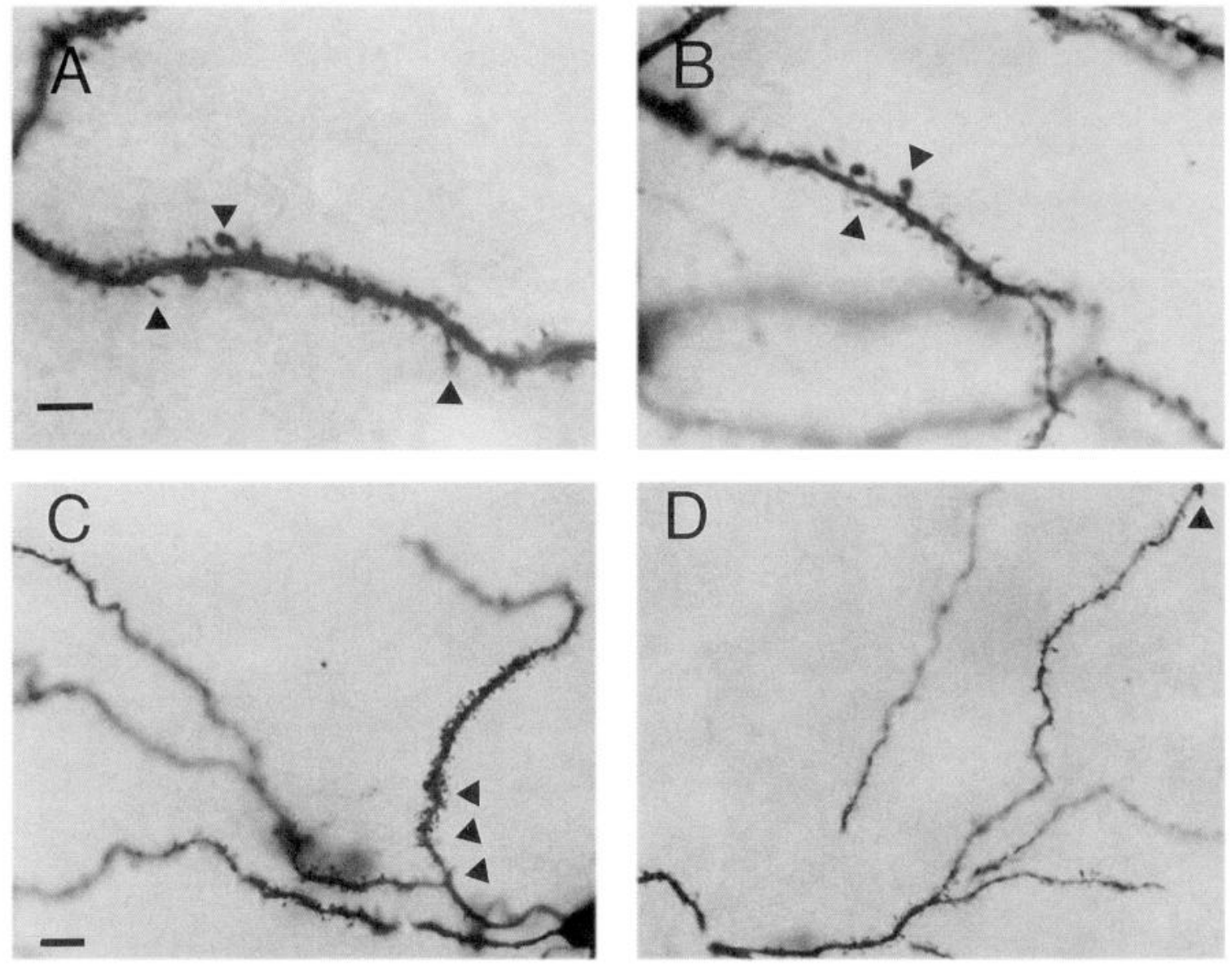

Figure 5. High magnification photomicrographs of LY-immunoreacted dendritic segments in the intact $(A)$ and DA-depleted $(B)$ medial shell. Arrowheads point out the different shapes and sizes of spines. Segments pictured in $C$ and $D$ are derived from neurons in the intact and DAdepleted lateral shell, respectively. Arrowheads in $C$ point out the asymmetry in spine distribution along the segment, and arrowhead in $D$ points to cone-like termination of the dendrite. Scale bar in $A$ is valid for $B$ and equals $10 \mu \mathrm{m}$, and scale bar in $C$ is valid for $D$ and equals $10 \mu \mathrm{m}$.

$50 \mu \mathrm{m}$ is decreased significantly in the DA-depleted side not only in the core and lateral shell $(t=5.41$, df $=225, p<$ 0.0001 ) but also in the medial shell ( $t=2.51$, df $=207, p<$ $0.01)$. After DA-depletion, segments greater than $50 \mu \mathrm{m}$ in length have reduced numbers of spines in the lateral $(p<0.05$, Mann-Whitney $U$ ) but not the medial shell and segments are significantly more tortuous in the medial shell $(p=0.001$, Mann-Whitney $U$ ).

The statistical tests (see above and Table 1) include values for aspiny proximal dendritic segments as well as for some segments that have been artificially truncated in the preparation of the slice. In order to limit the contribution of such presumably invalid measurements to the statistical analysis of length, the data were edited in the following manner. Segments with spine densities outside 2 standard deviations, as calculated for segments greater than $50 \mu \mathrm{m}$ in length, were removed from each group. Statistical comparisons of these filtered samples revealed that in the core, dendritic segments are $16 \%$ shorter on the DAdepleted side (median length $=48$ ) as compared to the intact side (median length $=55)$ and the decrease is significant $(p=$ 0.038 , Mann-Whitney $U$ ). Further in the core, the density $(t=$ 7.46 , $\mathrm{df}=737, p<0.0001)$ and numbers $(p<0.0001$, MannWhitney $U$ ) of spines are significantly reduced in the DA-depleted side. In the lateral shell, tests with the edited data revealed that segments do not change in length but decrease significantly in the density $(t=7.26$, df $=411, p<0.0001)$ and number $(p$ $<0.0001$, Mann-Whitney $U$ ) of spines after DA depletion. Edited data in the medial shell reveal that the median length of segments on the DA-depleted side (median length $=59$ ) is $23 \%$ greater than that on the intact side (median length $=48$ ); however, this difference is not significant ( $p=0.12$, Mann-Whitney $U)$. Nevertheless, spine density decreases significantly $(t=3.36$, df $=375, p<0.001)$ in the DA-depleted as compared to the intact medial shell, while the number of spines per segment remains unchanged.

\section{Discussion}

Dendrites and their spines are the principal targets for synaptic input to striatal neurons (Wilson et al., 1983; Bolam, 1984). Accordingly, any remodeling of these structures in response to deafferentation or neurotransmitter deficits would be expected to compromise the functional integrity of striatal circuits. Indeed, changes in dendritic morphology could contribute, at least in part, to cognitive and motor deficits observed with certain neurodegenerative disorders as well as to the effects, both efficacious and undesirable, of neuroleptic drug treatment. The data presented in this report show that accumbal spiny neurons undergo morphological change following a lesion of the striatal dopaminergic innervation and that neurons in the shell and core are differentially affected by dopamine depletion. 


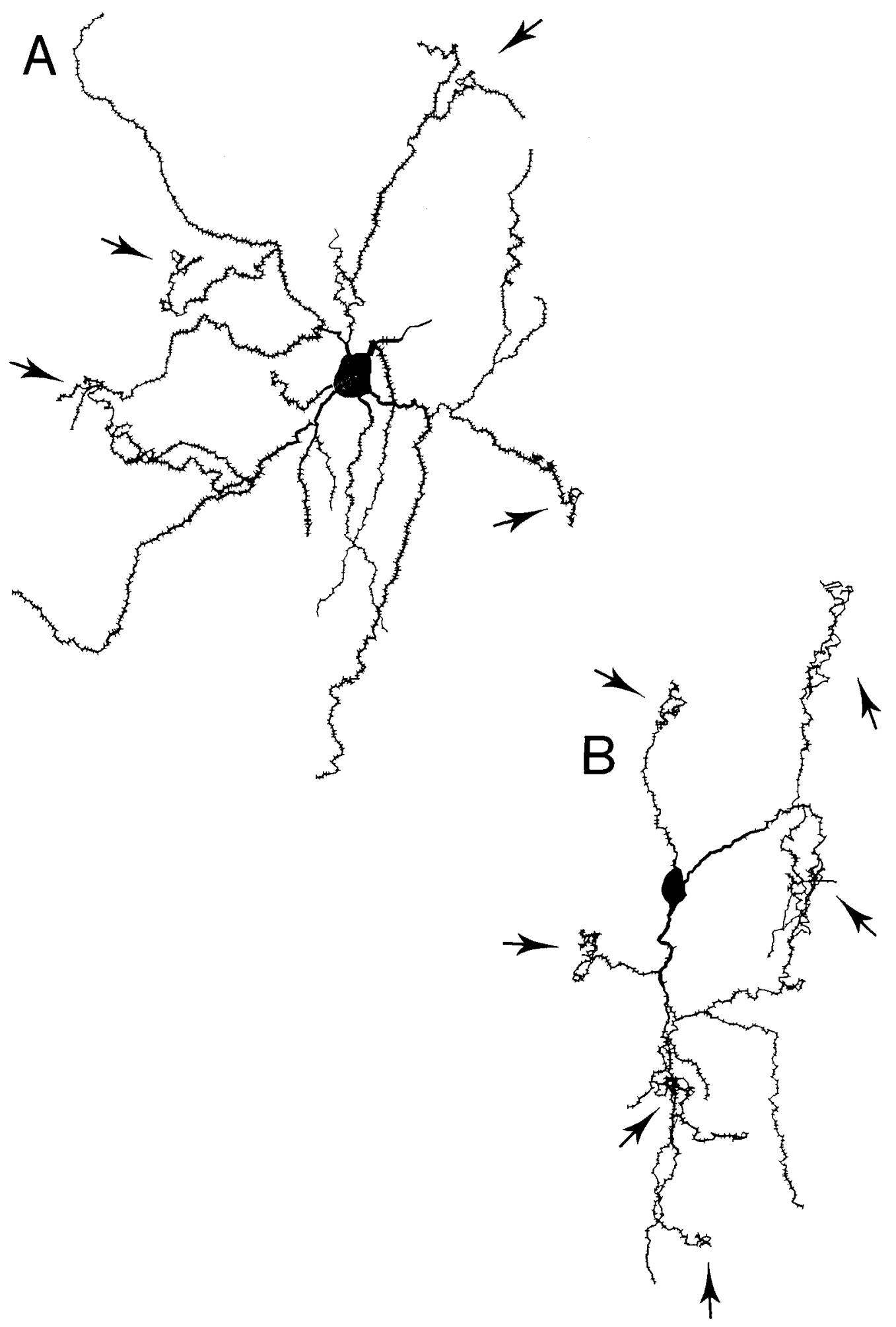

Figure 6. Reconstructions of LY-immunoreacted neurons in the DA-depleted core $(A)$ and medial shell $(B)$. Arrows point to recurved and twisted parts of some dendritic segments. Note that the tortuous segments in $(A)$ in the second or third branch order.

A midbrain lesion with 6-OHDA effectively destroys dopaminergic axons in the MFB. Desmethylimipramine injected shortly before the toxin may reduce noradrenergic depletion (Breese and Traylor, 1971) but probably does not prevent degeneration of all noradrenergic fibers nor spare the serotonergic pathway. Furthermore, various types of fibers may be damaged at the injection sitc. Therefore, the morphological changes presented here cannot be linked incontrovertibly to dopamine and may be associated with the loss of other transmitter systems. Nevertheless, since unilateral, nigral lesions with ibotenic acid produce a pattern of striatal tyrosine hydroxylase depletion resembling that with nigral 6-OHDA le- 
Table 1. Median values and (range) of the length, tortuosity, spine density and numbers of spines for dendritic segments in the lesioned and intact shell and core

\begin{tabular}{|c|c|c|c|c|c|}
\hline Territory & $n^{\prime \prime}$ & $\begin{array}{l}\text { Length } \\
(\mu \mathrm{m})\end{array}$ & $\begin{array}{l}\text { Tortu- } \\
\text { osity } \\
\text { ratio }\end{array}$ & $\begin{array}{l}\text { Spine } \\
\text { density } \\
\text { spines/10 } \\
\mu \mathrm{m}\end{array}$ & $\begin{array}{l}\text { Spines } \\
\text { per } \\
\text { segment }\end{array}$ \\
\hline \multicolumn{6}{|c|}{ Accumbens, total } \\
\hline Intact & 1103 & $\begin{array}{l}37 \\
(1-310)\end{array}$ & $\begin{array}{c}1.48 \\
(I \cdots 3.84)\end{array}$ & $\begin{array}{l}10.3 \\
(0-34.1)\end{array}$ & $\begin{array}{l}38 \\
(0 \quad 359)\end{array}$ \\
\hline Lesioned & 1085 & $\begin{array}{l}33 \\
(1-326)\end{array}$ & $\begin{array}{c}1.54 * * * \\
(1-5.35)\end{array}$ & $\begin{array}{c}8.7 * * * * \\
(0-31.3)\end{array}$ & $\begin{array}{l}32 \\
(0-414)\end{array}$ \\
\hline \multicolumn{6}{|l|}{ Core } \\
\hline Intact & 485 & $\begin{array}{l}39 \\
(1-258)\end{array}$ & $\begin{array}{l}1.52 \\
(1-3.84)\end{array}$ & $\begin{array}{l}11.1 \\
(0-29.7)\end{array}$ & $\begin{array}{l}50 \\
(0-359)\end{array}$ \\
\hline Lesioned & 528 & $\begin{array}{l}31 \\
(1-254)\end{array}$ & $\begin{array}{l}1.54 \\
(1-5.35)\end{array}$ & $\begin{array}{c}9.0 * * * \\
(0-31.3)\end{array}$ & $\begin{array}{l}39 * * \\
(0-414)\end{array}$ \\
\hline \multicolumn{6}{|l|}{ Shell, total } \\
\hline Intact & 618 & $\begin{array}{l}36 \\
(1-310)\end{array}$ & $\begin{array}{c}1.44 \\
(1-3.14)\end{array}$ & $\begin{array}{c}9.7 \\
(0-34.1)\end{array}$ & $\begin{array}{l}34 \\
(0-344)\end{array}$ \\
\hline Lesioned & 557 & $\begin{array}{l}34 \\
(1-326)\end{array}$ & $\begin{array}{c}1.54 \% * \\
(1-4.3)\end{array}$ & $\begin{array}{c}8.4 * * * \\
(0-24.0)\end{array}$ & $\begin{array}{l}32 \\
(0-262)\end{array}$ \\
\hline \multicolumn{6}{|l|}{ Medial shell } \\
\hline Intact & 334 & $\begin{array}{l}35 \\
(1-310)\end{array}$ & $\begin{array}{c}1.44 \\
(1-3.14)\end{array}$ & $\begin{array}{l}8.8 \\
(0-20.9)\end{array}$ & $\begin{array}{l}28 \\
(0-344)\end{array}$ \\
\hline Lesioned & 236 & $\begin{array}{l}43 \\
(1-326)\end{array}$ & $\begin{array}{l}1.65^{* * *} \\
(1-4.3)\end{array}$ & $\begin{array}{l}8.1 \\
(0-24.0)\end{array}$ & $\begin{array}{l}37 \\
(0-262)\end{array}$ \\
\hline \multicolumn{6}{|l|}{ Lateral shell } \\
\hline Intact & 284 & $\begin{array}{l}38 \\
(1-209)\end{array}$ & $\begin{array}{l}1.44 \\
(1-2.73)\end{array}$ & $\begin{array}{l}10.8 \\
(0-34.1)\end{array}$ & $\begin{array}{l}44 \\
(0-292)\end{array}$ \\
\hline Lesioned & 321 & $\begin{array}{l}29 \\
(1-242)\end{array}$ & $\begin{array}{l}1.46 \\
(1-4.15)\end{array}$ & $\begin{array}{l}8.6^{* * * *} \\
(0-20)\end{array}$ & $\begin{array}{l}25^{*} \\
(0-238)\end{array}$ \\
\hline
\end{tabular}

" $n$, Number of dendritic segments pooled for analysis.

"Tortuosity is defined as a ratio: segment length/radial distance from start to end of a segment. *, $p<0.05 ; * *, p<0.01$; ***, $p<0.001$; differ with respect to control values (Mann-Whitney $U$ ).

sions (Zahm, 1991), the structural changes could involve the loss of dopamine.

\section{Data analysis: critique and interpretations}

The normal structural variability of medium spiny neurons in nucleus accumbens is great (Bayer, 1981; Rueda et al., 1986; Meredith et al., 1992 and present results). For many parameters, differences between DA-depleted and intact hemispheres could be demonstrated with values derived from individual cells (unpublished observations) but since all parameters were measured at the level of the dendritic segment and since the greater sample sizes generated by pooled segments were required to reveal significant differences in certain features that otherwise would have gone unobserved, the dendritic segment was chosen as the optimal unit of comparison (see also, Meredith et al., 1992).

Straightforward quantitative analysis of the present data was confounded by several features of medium spiny neurons and by the methods used in their preparation. Insofar as spines typically appear at or near the first branch point (Wilson et al., 1983), the most proximal segments are aspiny or have very low spine densities. Furthermore, as most filled cells lie near the surface of the slice, their superficial dendrites are often severed (Arts and Groenewegen, 1992). To simply eliminate truncated segments from the analysis is not possible because it is rarely clear whether segments near the surface terminate naturally or artificially. To reject segments due to their proximity to the slice surface would potentially eliminate a considerable number of valid data points. Consequently, other criteria were applied in an effort to remove probable invalid segments.

As seen in Figure 7, the scatter of spine densities for segments shorter than $50 \mu \mathrm{m}$ is large and presumably reflects the presence of truncated and aspiny segments. Rapid and dramatic changes (increases) in spine density occur along the proximal $60 \mu \mathrm{m}$ of a dendrite (Wilson et al., 1983) and frequently, spines are unevenly distributed on segments, especially in the DA-depleted hemisphere (present results). Truncation of a dendrite may therefore produce an abnormally high or low index of segment spine density depending on where the dendrite has been severed. Such peaks and valleys in spine density typically average out for segments longer than $50 \mu \mathrm{m}$. Moreover, there is no reason to expect that spine-laden and aspiny segments respond similarly to DA loss. Consequently, segments were accepted only if their spine density fell within 2 SDs of the group mean as calculated for segments longer than $50 \mu \mathrm{m}$. By treating the data in this way, the probability of retaining valid segments and rejecting invalid outlicrs was maximized.

\section{Region-specific structural changes following DA depletion}

Morphological changes were evident in the core, where a near total loss of DA was associated with shortened dendrites and spine loss, and in the lateral shell, where DA depletion was associated with fewer spines. However, in the medial shell, where, coincidently, the loss of tyrosine hydroxylase-immunoreactive fibers was substantial but never complete, higher dendritic tortuosities and lower spine densities were apparent in comparison to controls. Since the significant decline in density was not accompanied by a loss of spines, dendritic lengthening, although insignificant in tests, could account for the decline.

Lesions of the MFB with 6-OHDA ultimately cause considerable loss of DA-containing axon terminals in the entire striatal complex. The loss of these terminals, however, seems to occur more rapidly in somc parts of the striatum than in others during the first 2 weeks postlesion (Zahm, 1991). Indeed, DA axons in the shell, and especially its medial part, seem to degenerate less rapidly and less completely (present data) than do those in the core (Zahm, 1991). Furthermore, the integrity of the crossed DA projection (Douglas et al., 1987; Stein et al., 1992) may also be responsible for the residual fibers. Nevertheless, changes in shell and core dendrites presumably reflect the differential distribution of DA inputs (Zahm, 1992) or may be related to extracellular DA levels. Microdialysis experiments have shown that DA depletion must exceed $80 \%$ before diminished extracellular DA can be measured (Stachowiak et al., 1987; Robinson and Whishaw, 1988) which suggests that following a partial lesion, increased release and/or diminished uptake by residual terminals compensates for the loss caused by the lesion (Zigmond et al., 1990). Thus, the mitigating influence of remaining, intact DA terminals may be sufficient to preserve spines and bring about increases in dendritic tortuosity in the medial shell but not in the core or lateral shell. However, the available evidence is probably insufficient to conclude that residual DA stimulates dendritic growth since striatal dendrites are reported to atrophy in Parkinsonian patients treated with L-dopa (McNeill et al., 1988) and DA added to cultures causes neurite retraction (Lankford et al., 1988).

Dendritic growth occurs in the striatum of aging mice (Rafols 


\section{Control Hemisphere}
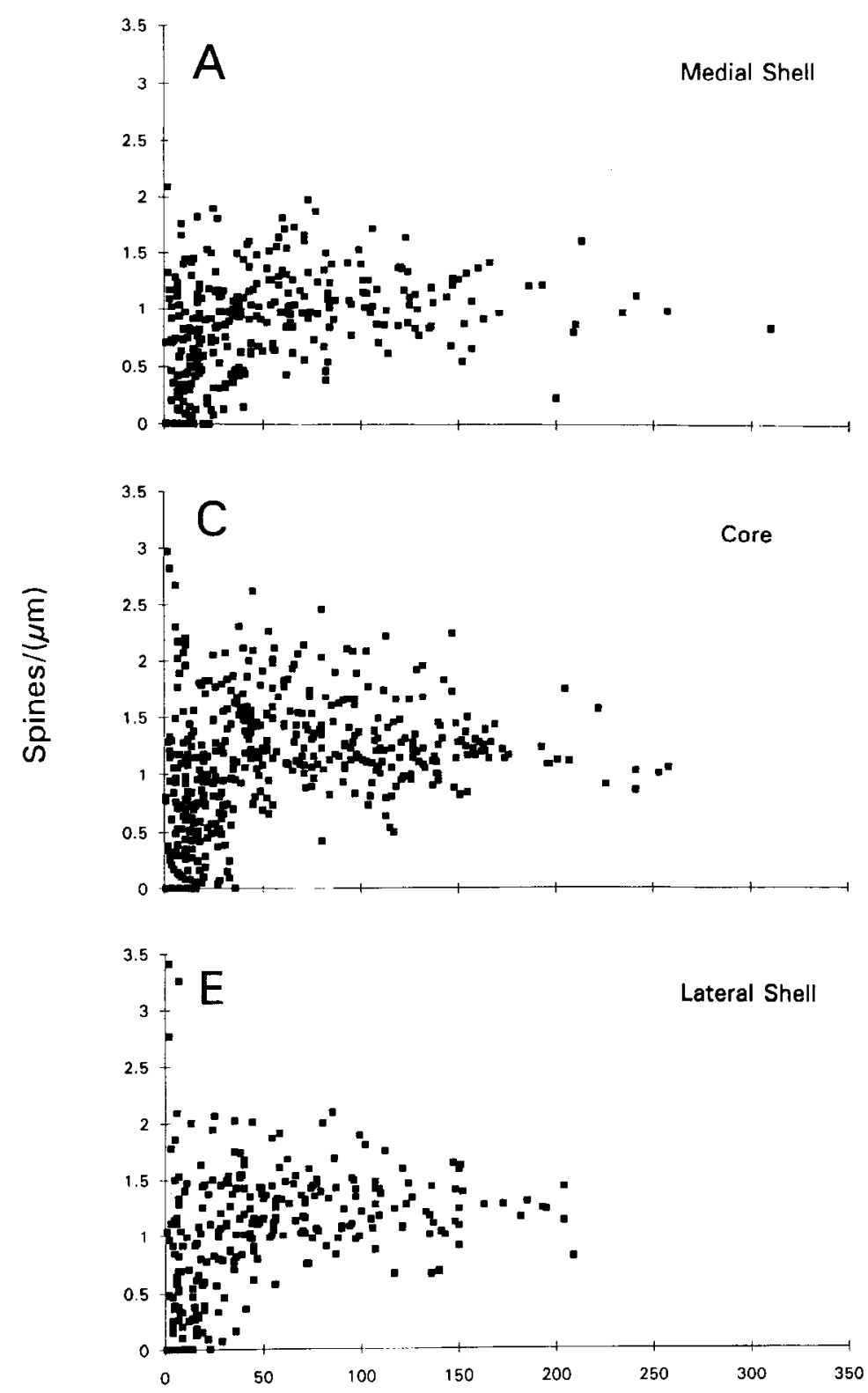

\section{Dopamine-depleted Hemisphere}
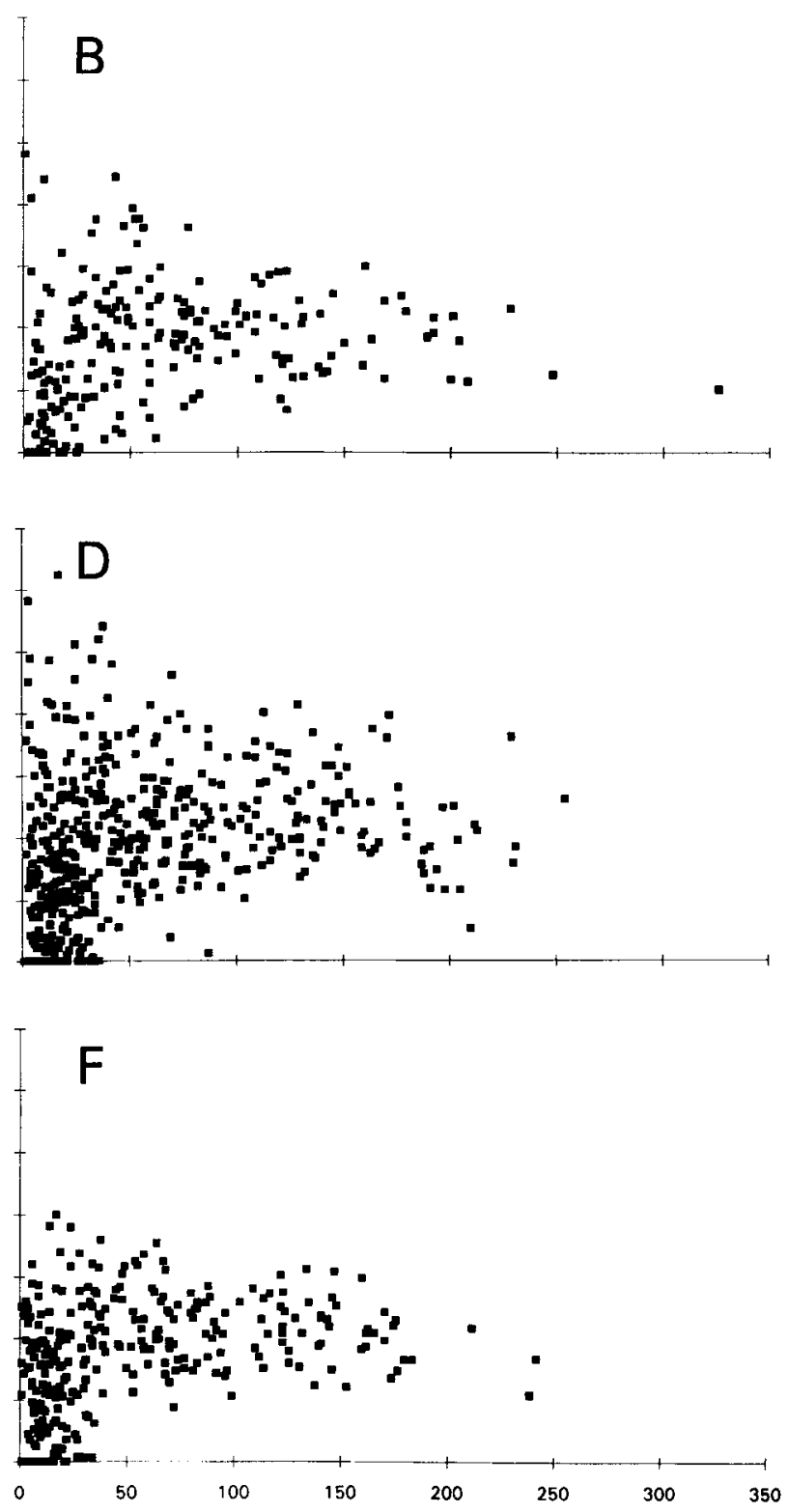

\section{Segment Length $(\mu \mathrm{m})$}

Figure 7. Scatterplots generated using original pooled data from the intact and DA-depleted medial shell $(A, B)$, core $(C, D)$ and lateral shell $(E$, $F$ ). Segment length is represented on the abscissa and spine density on the ordinate.

et al., 1989; McNeill et al., 1990), in hippocampal neurons of aged humans (Buell and Coleman, 1981; Flood et al., 1985, 1987), and in striatal cells in moderate grade Huntington's disease (Graveland et al., 1985; Ferrante et al., 1991). In each of these instances, however, the effects are transient and dendritic proliferation is followed by degeneration. Deafferented neurons may initially attempt to compensate with dendritic growth but probably independent of the actions of DA. Thus, it is unclear whether the changes observed in the shell reflect the timc coursc, extent of lesion or a response exhibited exclusively by those neurons. In this regard, there is some evidence that core and medial shell cells comprise distinct populations, the former being purely striatal in nature and the latter having neuronal phenotypes belonging instead to the extended amygdala (Alheid and Heimer, 1988; Heimer and Alheid, 1991).

\section{Potential mechanisms underlying dendritic remodeling}

Little is known about the mechanisms involved in neurotransmitter-induced alterations of dendritic structure. Certainly, any major deafferentation can induce dendritic atrophy (Kemp and 
Powell, 1971; Lund, 1978; Caceres and Steward, 1983; Deitch and Rubel, 1984). Catecholamines can influence the growth of neurites (Haydon et al., 1984; Lankford et al., 1987, 1988; Davenport et al., 1993), presumably through (de)activation of second messenger systems that open calcium $\left[\mathrm{Ca}^{2+}\right]$ channels (Doroshenko et al., 1982). Even though a rise in intracellular $\left[\mathrm{Ca}^{2+}\right]$ has been implicated in neurite outgrowth (Cohan et al., 1987; Mattson and Kater, 1987), substantial increases cause neurite retraction (Mattson, 1988; Choi, 1988) and are toxic to dendrites in vivo (Meyer, 1989). Dopamine-depleting lesions of nucleus accumbens are associated with great increases in cAMP (Tassin et al., 1982) and, in the core, cause an upregulation of DA receptors (Jongen-Rêlo et al., 1994) that stimulate adenyl cyclase activity (Stoof and Kebabian, 1984). Even though $\left[\mathrm{Ca}^{2+}\right]$ buffers quickly return intraspinous $\left[\mathrm{Ca}^{2+}\right]$ levels to baseline (Guthrie et al., 1991), spines may succumb to excitotoxicity. Dopamine depletion is associated with spine loss in the accumbal core and lateral shell (present study) and in the dorsal striatum (Ingham et al., 1989). Corticostriatal, presumably glutamatergic, terminals contact the heads of spines that often receive DA synapses on their necks (Totterdell and Smith, 1989; Meredith and Wouterlood, 1990; Sesack and Pickel, 1990). Since the DA input appears to modulate the corticostriatal input (Brown and Arbuthnott, 1983; Pennartz et al., 1992a), its removal may produce excitotoxic conditions that result in spine loss. Certainly, small increases of glutamate underlie spine swelling and loss in hippocampal slices (Siman and Card, 1988).

Functional implications of structural changes in shell and core neurons

Recognition of structural change after a lesion requires that proper controls have been employed. For neurons in the intact hemisphere to serve as valid controls, they should not differ morphologically from those in unlesioned animals. The results of interterritorial comparisons made within the intact nucleus accumbens (present study) compare favorably with those published earlier for unlesioned animals (Meredith et al., 1992), in that present measures of dendritic segment length are similar in the accumbal territories, while spine density differs significantly not only between shell and core but also between medial and lateral shell and medial shell and core.

The present data and those of others (Deutch and Cameron, 1991; Pennartz et al., 1992b; O’Donnell and Grace, 1993) suggest that shell and core circuits should respond differently to alterations in DA neurotransmission. Atypical neuroleptic blockade of DA receptors increase Fos expression differentially in the shell and core (Deutch et al., 1992) and mild restraint stress selectively increases DA utilization in the shell (Deutch and Cameron, 1991). Systemically administered cocaine, which enhances extracellular levels of DA in this nucleus, increases the number of Fos-positive neurons in the core as compared to the shell (Graybiel et al., 1993). Thus, the region-specific morphological responses to the depletion of DA and perhaps other monoamines, demonstrated in the present study may reflect specific neurotransmitter-substrate interactions. Further work is clearly needed to establish the precise mechanism(s) involved.

\section{References}

Alheid GF, Heimer L (1988) New perspectives in basal forebrain organization of special relevance for neuropsychiatric disorders: the striatopallidal, amygdaloid and corticopetal components of substantia innominata. Neuroscience 27:1-39.

Anden N-E, Dahlstrom A, Fuxe K, Larsson K, Olson L, Ungerstedt U
(1966) Ascending monoamine neurons to the telencephalon and diencephalon. Acta Physiol Scand 67:313-326.

Arts MPM, Groenewegen HJ (1992) Relationships of the dendritic arborizations of ventral striato-mesencephalic projection neurons with boundaries of striatal compartments. An in vitro intracellular labeling study in the rat. Eur $J$ Neurosci $4: 574-588$.

Bayer S $\Lambda$ (1981) $\Lambda$ correlated study of neurogenesis, morphogenesis and cytodifferentiation in the rat nucleus accumbens. In: The neurobiology of the nucleus accumbens (Chronister RB, De France JF, eds), pp 173-197. Brunswick, ME: Haer Institute.

Beckstead RM, Domesick VB, Nauta WJH (1979) Efferent connections of the substantia nigra and ventral tegmental area in the rat. Brain Res 175:191-217.

Bolam JP (1984) Synapses of identified neurons in the neostriatum. In: Ciba Foundation symposium 107, Functions of the basal ganglia (Fvered D, O'Connor M, eds), pp 30-42. London: Pitman.

Breese GR, Traylor TD (1971) Depletion of brain noradrenaline and dopamine by 6-hydroxydopamine. Br J Pharmacol 42:88-99.

Brown JR, Arbuthnott GW (1983) The electrophysiology of dopamine $\left(D_{2}\right)$ receptors: a study of the actions of dopamine on corticostriatal transmission. Neuroscience 10:349-355.

Buell SJ, Coleman PD (1981) Quantitative evidence for selective dendritic growth in normal human aging but not in senile dementia. Brain Res 214:23-41.

Caceres A, Steward O (1983) Dendritic reorganization in the denervated dentate gyrus of the rat following entorhinal cortical lesions: a Golgi and electron microscopic analysis. J Comp Neurol 214:387403.

Choi DW (1988) Calcium-mediatcd ncurotoxicity: rclationship to specific channel types and role in ischemic damage. Trends Neurosci 11: 465-469.

Cohan CS, Connor JA, Kater SB (1987) Electrically and chemically mediated increases in intracellular calcium in neuronal growth cones. J Neurosci 7:3588-3599.

Davenport RW, Dou P, Rehder V, Kater SB (1993) A sensory role for neuronal growth cone filopodia. Nature 361:721-724.

Deitch IS, Rubel EW (1984) Afferent influences on brain stem auditory nuclei of the chicken: time course and specificity of dendritic atrophy following deafferentation. J Comp Neurol 229:66-79.

Denlau JM, Menetrey A, Thierry AM (1994) Indirect nucleus accumbens input to the prefrontal cortex via the substantia nigra pars reticulata: a combined anatomical and electrophysiological study in the rat. Neuroscience 61:533-545.

Deutch AY, Cameron DS (1991) Pharmacological characterization of dopamine systems in the nucleus accumbens core and shell. Neuroscience 46:49-56.

Deutch AY, Goldstein M, Baldino F, Roth RH (1988) Telencephalic projections of the A8 dopamine cell group. Ann NY Acad Sci 537: 27-50.

Deutch AY, Lee MC, Iadorola MJ (1992) Regionally specific effects of atypical antipsychotic drugs on striatal Fos expression: the nucleus accumbens shell as a locus of antipsychotic action. Mol Cell Neurosci 3:332-341.

Dilts RP Jr, Helton TE, McGinty JF (1993) Selective induction of Fos and FRA immunoreactivity within the mesolimbic and mesostriatal dopamine terminal fields. Synapse 13:251-263.

Doroshenko PA, Kostyuk PG, Martynyuk AE (1982) Intracellular metabolism of adenosine $3^{\prime}: 5^{\prime}$-cyclic monophosphate and calcium inward current in perfused neurons of Helix pomatia. Neuroscience 7:2125-2134

Douglas R, Kellaway L, Mintz M, van Wageningen G (1987) The crossed nigrostriatal projection decussates in the ventral tegmental decussation. Brain Res 418:111-121.

Ferrante RJ, Kowall NW, Richardson EP (1991) Proliferative and degenerative changes in striatal spiny neurons in Huntington's disease: a combined study using the section-Golgi method and calbindin D28k immunocytochemistry. J Neurosci 11:3877-3887.

Flood DG, Buell SJ, Defiore CH, Horwitz GJ, Coleman PD (1985) Age-related dendritic growth in dentate gyrus of human brain is followed by regression in the 'oldest old'. Brain Res 345:366-368.

Flood DG, Buell SJ, Horwitz GJ, Coleman PD (1987) Dendritic extent in human CA $2 / 3$ hippocampal pyramidal neurons in norman aging and senile dementia. Brain Res 409:88-96.

Graveland GA, Williams RS, DiFiglia MA (1985) Evidence for de- 
generative and regenerative changes in neostriatal spiny neurons in Huntington's disease. Science 227:770-773.

Graybiel AM, Moratalla R, Robertson HA (1993) Amphetamine and cocaine induce drug-specific activation of the $c$-fos gene in striosomematrix compartments and limbic subdivisions of the striatum. Proc Natl Acad Sci USA 87:6912-6916.

Groenewegen HJ, Berendse HW (1990) Connections of the subthalamic nucleus with ventral striatopallidal parts of the basal ganglia in the rat. J Comp Neurol 294:607-622.

Groenewegen HJ, Russchen FT (1984) Organization of the efferent projections of the nucleus accumbens to pallidal, hypothalamic, and mesencephalic structures: a tracing and immunohistochemical study in the cat. J Comp Neurol 223:347-367.

Groenewegen HJ, Berendse HW, Meredith GE, Haber SN, Voorn P, Wolters JG, Lohman AHM (1991) Functional anatomy of the ventral, limbic system innervated striatum. In: The mesolimbic dopamine system: from motivation to action (Willner P, Scheel-Kruger J, eds), IP 19-59. Chichester: Wiley.

Groenewegen HJ, Berendse HW, Wouterlood FG (1994) Organization of the projections from the ventral striato-pallidal system to ventral mesencephalic dopaminergic neurons in the rat. In: The basal ganglia IV (Percheron G, McKenzie JS, Féger J, eds), pp 81-93. New York: Plenum.

Guthrie PB, Segal M, Kater SB (1991) Independent regulation of calcium revealed by imaging dendritic spines. Nature 354:76-80.

Haydon PG, McCobb DP, Kater SB (1984) Serotonin selectively inhibits growth cone motility and synaptogenesis of specific identified neurons. Science 226:561-564.

Hefti F, Melamed E, Wurtman RJ (1980) Partial lesions of the dopaminergic nigrostriatal system in rat brain: biochemical characterization. Brain Res 195:123-137.

Heimer L, Alheid GF (1991) Piecing together the puzzle of basal forebrain anatomy. In: The basal forebrain: anatomy to function (Napier TC, Kalivas PW, Hanin I, eds), pp 1-42. New York: Plenum.

Heimer L, Alheid GF, Zaborsıky L (1985) Basal ganglia. In: The rat nervous system, Vol 1, Forebrain and midbrain (Paxinos G, ed), pp 37-86. Sydney: Academic.

Heimer L, Zahm DS, Churchill L, Kalivas PW, Wohltman C (1991) Specificity in the projection patterns of accumbal core and shell in the rat. Neuroscience 41:89-125.

Ingham CA, Hood SH, Arbuthnott GW (1989) Spine density on neostriatal neurones changes with 6-hydroxydopamine lesions and with age. Brain Res 503:334-338.

Ingham CA, Hood SH, Arbuthnott GW (1991) A light and electron microscopical study of enkephalin-immunoreactive structures in the rat neostriatum after removal of the nigrostriatal dopaminergic pathway. Neuroscience 42:715-730.

Jongen-Relo AL, Docter GJ, Jonker AJ, Vreugdenhil E, Groenewegen HJ, Voorn P (1994) Differential effects of dopamine depletion on the binding and mRNA levels of dopamine receptors in the shell and core of the rat nucleus accumbens. Mol Brain Res 25:333-343.

Kemp JM, Powell TPS (1971) The termination of fibres from the cerebral cortex and thalamus upon dendritic spines in the caudate nucleus: a study with the Golgi method. Philos Trans R Soc Lond [Biol] 262:429-439.

Lankford K, DeMello FG, Klein WL (1987) A transient embryonic dopamine receptor inhibits growth cone motility and neurite outgrowth in a subset of avian retina neurons. Neurosci Lett 75:169174.

Lankford KL, De Mello FG, Klein WL (1988) $D_{1}$-type dopamine receptors inhibit growth cone motility in cultured retina neurons: evidence that neurotransmitters act as morphogenic growth regulators in the developing central nervous system. Proc Natl Acad Sci USA 85: 2839-2843.

Lund RD (1978) Development and plasticity of the brain. An introduction. New York: Oxford UP.

Maldonado-Irizarry CS, Kelley AE (1993) Evidence for behavioral dissociation between "core" and "shell" subregions of the nucleus accumbens following microinjections of DNQX, a non-NMDA antagonist. Soc Neurosci Abstr 19:812.

Mattson MP (1988) Neurotransmitters in the regulation of neuronal cytoarchitecture. Brain Res Rev 13:179-212.

Mattson MP, Kater SB (1987) Calcium regulation of neurite elongation and growth cone motility. J Neurosci 7:4034-4043.

McNeill TH, Brown SA, Rafols JA, Shoulson I (1988) Atrophy of medium spiny I striatal dendrites in advanced Parkinson's disease. Brain Res 455:148-152.

McNeill TH, Koek LL, Brown SA, Rafols JA (1990) Quantitative analysis of age related dendritic changes in medium spiny I (MSI) striatal neurons of C57BL/6N Mice. Neurobiol Aging 11:537-550.

Meredith GE, Arbuthnott GW (1993) IBRO handbook series: methods in the neurosciences, Vol 16, Morphological investigations of single neurons in vitro. Chichester: Wiley.

Meredith GE, Wouterlood FG (1990) Hippocampal and midline thalamic fibers and terminals in relation to the choline acetyltransferaseimmunoreactive neurons in nucleus accumbens of the rat: a light and electron microscopic study. J Comp Neurol 296:204-221.

Meredith GE, Agolia R, Arts M, Groenewegen HJ, Zahm DS (1992) Morphological differences between the projection neurons in the core and shell of the nucleus accumbens in the rat. Neuroscience 50:149162.

Meyer FB (1989) Calcium, neuronal hyperexcitability and ischemic injury. Brain Res Rev 14:227-243.

Nauta WHJ, Domesick VB (1984) Afferent and efferent relationships of the basal ganglia. In: Functions of the basal ganglia (Evered D, O'Connor M, eds), pp 3-23. New York: Kaven.

O'Donnell P, Grace AA (1993) Dopaminergic modulation of dye- coupling between neurons in the core and shell regions of the nucleus accumbens. J Neurosci 13:3456-3471.

Pennartz CMA, Dolleman-Van der Weel MJ, Kitai ST, Lopes da Silva FH (1992a) Presynaptic dopamine D1 receptors attenuate excitatory and inhibitory limbic inputs to the shell region of the rat nucleus accumbens studied in vitro. J Neurophysiol 67:1325-1334.

Pennartz CMA, Dolleman-Van der Weel MJ, Lopes da Silva FH (1992b) Differential membrane properties and dopamine effects in the shell and core of the rat nucleus accumbens studied in vitro. Neurosci Lett 136:109-112.

Robinson TE, Whishaw IQ (1988) Normalization of extracellular dopamine in striatum following recovery from a partial unilateral 6-OHDA lesion of the substantia nigra: a microdialysis study in freely moving rats. Brain Res 450:209-224.

Rueda J, Prieto J, Juiz J, Angulo A (1986) A Golgi study on the nucleus accumbens septi of the rat. J Hirnforsch 27:515-520.

Sesack SR, Pickel VM (1990) In the rat medial nucleus accumbens, hippocampal and catecholaminergic terminals converge on spiny neurons and are in apposition to each other. Brain Res 527:266-279.

Siman R, Card JP (1988) Excitatory amino acid neurotoxicity in the hippocampal slice preparation. Neuroscience 26:433-447.

Stachowiak MK, Keller RW, Stricker EM, Zigmond MJ (1987) Increased dopamine efflux from striatal slices during development and after nigrostriatal bundle damage. J Neurosci 7:1648-1654.

Steiner H, Weiler H-T, Morgan S, Huston JP (1992) Time- dependent neuroplasticity in mesostriatal projections after unilateral removal of vibrissae in the adult rat: compartment-specific effects on horseradish peroxidase transport and cell size. Neuroscience 47:793-806.

Stoof JC, Kebabian JW (1984) Two dopanine receptors: biochemistry, physiology and pharmacology. Life Sci 35:2281-2296.

Taghert PH, Bastiani MJ, Ho RK, Goodman CS (1982) Guidance of pioneer growth cones: filopodial contacts and coupling revealed with an antibody to Lucifer Yellow. Dev Biol 94:391-399.

Tassin JP, Simon H, Hervé D, Blanc G, Le Moal M, Glowinski J, Bockaert J (1982) Non-dopaminergic fibres may regulate dopamine-sensitive adenylate cyclase in the prefrontal cortex and nucleus accumbens. Nature 295:696-698.

Totterdell S, Smith AD (1989) Convergence of hippocampal and dopaminergic input onto identified neurons in the nucleus accumbens of the rat. J Chem Neuroanat 2:285-298.

Voorn P, Jorritsma-Byham B, van Dijk C, Buijs RM (1986) The dopaminergic innervation of the ventral striatum in the rat: a light and electronmicroscopical study with antibodies against dopamine. J Comp Neurol 251:84-99.

Wilson CJ, Groves PM, Kitai ST, Linder IC. (1983) Three- dimensional structure of dendritic spines in the rat neostriatum. J Neurosci 3:383398

Zahm DS (1991) Compartmcnts in rat dorsal and ventral striatum revealed following injection of 6-hydroxydopamine into the ventral mesencephalon. Brain Res 552:164-169.

Zahm DS (1992) An electron microscopic morphometric comparison of the tyrosine hydroxylase immunoreactive innervation in the neo- 
striatum and nucleus accumbens core and shell. Brain Res 575:342346.

Zahm DS, Brog JS (1992) On the significance of subterritories in the "accumbens" part of the rat ventral striatum. Neuroscience 50:751767.

Zahm DS, Heimer L (1990) Two transpallidal pathways originating in rat nucleus accumbens. J Comp Neurol 302:437-446.
Zahm DS, Heimer L (1993) Specificity in the efferent projections for the nucleus accumbens in the rat: comparison of the rostral pole projection patterns with those of the core and shell. J Comp Neurol 327: 220-232.

Zigmond MJ, Abercrombie ED, Berger TW, Grace AA, Stricker EM (1990) Compensations after lesions of central dopaminergic neurons: some clinical and basic implications. Trends Neurosci 13:290-296. 